\title{
PKM Meningkatkan Prestasi Siswa-siswi Panti Asuhan Berbasis Implementasi Model Hypnoedukasi
}

\author{
${ }^{1}$ Dewi Puspaningtyas Faeni, ${ }^{2}$ Ratih Puspitaningtias Faeni, \\ ${ }^{3}$ Retno Fuji Oktaviani, ${ }^{4}$ Rinny Mediyustiani \\ ${ }^{1,2,3,4}$ Fakultas Ekonomi dan Bisnis-Universitas Budi Luhur \\ Author E-mail: dewifaeni@budiluhur.ac.id
}

\begin{abstract}
A B S T R A K
Hypnoedukasi merupakan salah satu metodologi pembentukan karakter anak untuk mau belajar, disiplin terhadap waktu, sopan santun dan berprestasi. Pengabdian kepada masyarakat kali ini adalah dengan mengunjungi dua panti asuhan Rahmatan Lil Allamiin di Jonggol dan panti asuhan Baiturrahman di Serang - Jawa Barat. Kedua panti asuhan ini memiliki banyak persamaan yaitu anakanak di tempat ini rata-rata tidak memiliki rasa percaya diri yang berpengaruh pada prestasinya yang rendah. Untuk itu hypnoedukasi diimplementasikan pada anak-anak di panti dalam kurun waktu 3 bulan, maka sugesti dapat diinsersi ke alam bawah sadar anak-anak tersebut. Alhasil, setelah pertemuan ketiga, nilai-nilai ulangan dari apa yang mereka pelajari mengalami peningkatan yang sangat pesat. Bukan hanya prestasi yang meningkat, rasa percaya diri dan motivasi menjadi orang yang sukses pun mulai muncul pada diri mereka masing-masing.
\end{abstract}

Kata Kunci: Hypnoedukasi, Prestasi, Sugesti Positif, Alam Bawah Sadar, Motivasi.

\section{A B S T R A C T}

Hypnoeducation is a methodology for children's character forming so they are willing to learn, be disciplined with time, have good manners and become great achievers. Our Community Service is to visit two Rahmatan Lil Allamiin orphanages in Jonggol and Baiturrahman, both in Serang - West Java. These orphanages have many things in common, namely the children in this place do not have the confidence so that it affects their low performance. For this reason, Hypnoeducation is implemented to the children in the institution within a period of 3 months, so suggestions can be inserted into the Subconscious mind of these children. As a result, after the third meeting, the repeat scores of what they learned experienced a very rapid increase. Not only did their achievements improve, their confidence and motivation to become successful people began to emerge in each of them.

Keywords: Hypnoeducation, Achievement, Positive Suggestion, Subconscious, Motivation.

Copyright (C) 2020 Authors. This is an open access article distributed under the Creative Commons Attribution License, which permits unrestricted use, distribution, and reproduction in any medium, provided the original work is properly cited.

\section{LATAR BELAKANG}

Yayasan Yatim Piatu Baiturahman dan Yayasan Rahmatan Lil Alamin terletak di Kecamatan Kasemen, Banten Lama-Serang dan Kecamatan
Jonggol, Jawa Barat. Dimana kedua lokasi yatim piatu tersebut tidak jauh dari pusat kota kabupaten. Kedua Yayasan Panti Asuhan tersebut 
dikelola dengan cara sangat sederhana, walaupun tampak bersih. Ketika pertama kali dilakukan survei dan pengabdian masyarakat pada tahun 2016, kon-disi kedua panti asuhan tersebut sangat memprihatinkan. Anak-anak yang ditampung dinpanti sebanyak 300 anak di Yayasan Rahmatan Lil Alamin dan 500 anak di Yayasan Baiturahman, dalam kondisi rumah penampungan yang sangat minim dan terkesan ala kadarnya yaitu di bantaran sungai dan di sepanjang pelataran rumah penduduk. Sejak itu dilakukan pemantauan terhadap prestasi sekolah anak-anak panti, didapatkan data yang sangat memprihatinkan. Adapun kondisi yang dapat dirumuskan adalah sebagai berikut:

1. Buruknya gizi anak-anak panti asuhan.

2. Buruknya kondisi kesehatan fisik anak-anak panti asuhan.

3. Rendahnya prestasi sekolah anak-anak.

4. Kurangnya pembinaan mengenai kesehatan dan kebersihan diri.

5. Kurangnya kesadaran belajar.

6. Sebagian besar anak-anak menderita TBC dan kudis.

7. Kondisi tempat penampungan yang minim dan kurang layak.

8. Biaya sekolah sering menunggak.

9. Hilangnya rasa percaya diri, karena hidup di panti asuhan.

Berdasarkan hasil dari analisis kondisi tersebut, maka dapat dipetakan sebagai berikut. Rendahnya prestasi anak-anak panti dikarenakan gizi buruk, lingkungan hidup yang kurang memadai dan hilangnya motivasi belajar. Kondisi lingkungan yang buruk ini berdampak negatif bagi perkembangan $p$ sikologis anak-anak panti.

Jumlah anak-anak panti di kedua yayasan tersebut adalah sebagai berikut:

\begin{tabular}{lllc}
\hline \multirow{2}{*}{$\begin{array}{c}\text { Nama Panti } \\
\text { Asuhan }\end{array}$} & \multicolumn{1}{c}{ Lokasi } & \multicolumn{2}{c}{ Jumlah Anak Panti } \\
\cline { 3 - 4 } $\begin{array}{l}\text { Yayasan } \\
\text { Baiturrahman }\end{array}$ & $\begin{array}{l}\text { Banten Lama } \\
\text { Serang }\end{array}$ & Wanita \\
\hline $\begin{array}{l}\text { Yayasan Rahmatan } \\
\text { Lil Allamin }\end{array}$ & Jonggol, Bogor & 111 & 189 \\
\hline
\end{tabular}

Adapun profil masing-masing mitra program PKM dapat kami jelaskan sebagai berikut:

\section{Profil Yayasan Baiturrahman}

Yayasan Baiturrahman adalah sebuah panti asuhan yang berbasis sosial di awal pendiriannya, panti ini hanya berawal dari sebuah gubuk kecil seluas $97 \mathrm{~m} 2$ yang berdiri tegak di bantaran sungai irigasi dari Departemen PU. Gubuk tersebut terdiri dari empat kamar kecil yang mampu menampung sekitar 203 anak. Dimalam hari anak-anak panti bergantian tidur di panjang emperan rumah-rumah warga. Penampungan ini merupakan ide dari sepasang suami istri yang merasa kasihan melihat anak-anak tanpa ibu dan bapak berkeliaran tanpa makan dan sang yang cukup, dengan berjalannya waktu banyak pihak yang merasa tergugah dan mulai mengucurkan bantuannya berupa bahan makanan pokok serta obat-obatan. Di tahun 2000 bersama-sama dengan komunitas Club Hypnosis Sehati, Departemen Hukum dan Perundang-undangan (Dephukham) serta Pemda setempat secara gotong royong mendirikan sebuat bangunan sederhana di atas lahan milik De-phukham. Lahan seluas 1000 meter adalah lahan yang diperuntukkan untuk menampung para napi yang telah menyelesaikan masa tahanannya. Sebagai lahan untuk bercocok tanam.

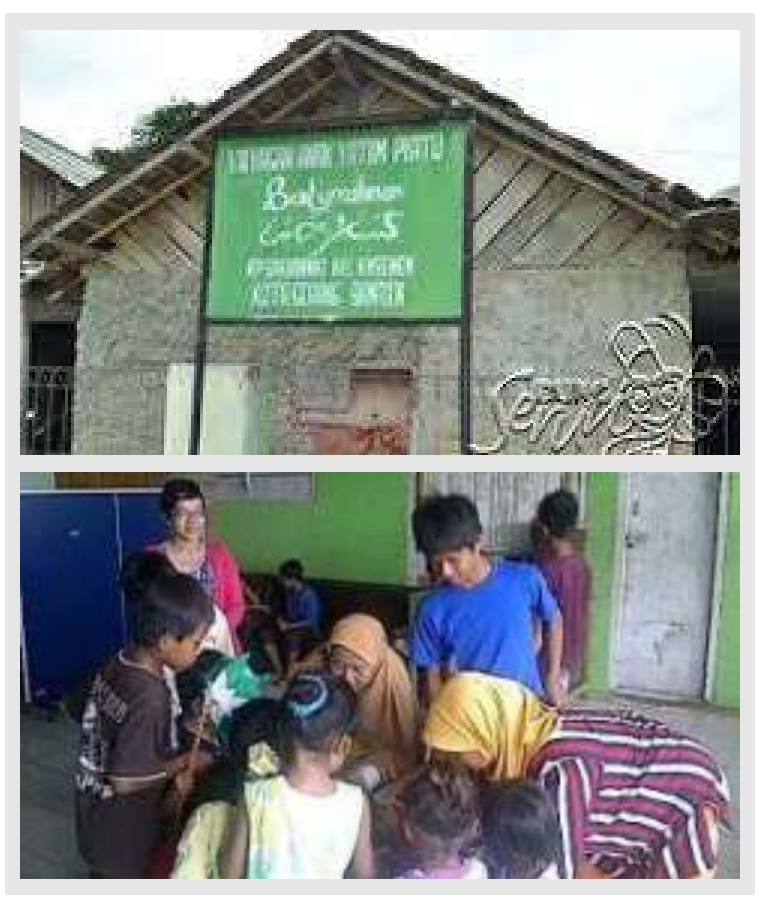


Adapun permasalahan yang ditemui di Yayasan Panti Asuhan Baiturrahman sebagai berikut:

1. Rendahnya prestasi sekolah.

2. Minimnya kemampuan dan ketrampilan dalam meningkatkan prestasi.

3. Keterbatasan fasilitas hidup, seperti tidak adanya ruang belajar.

4. Ruang bebas yang minim dan fasilitas yang minimalis.

5. Resiko tertular penyakit TBC, kudis, kekurangan gizi.

6. Rawan kecelakaan, karena lokasi di pinggir perlintasan kereta api.

7. Minimnya sarana prasarana yang dimiliki termasuk komputer dan printer serta belum memiliki scanner sebagai alat belajar.

Lebih jelasnya berkaitan dengan permasalahan tersebut dapat dilihat pada gambar 1 dibawah ini:

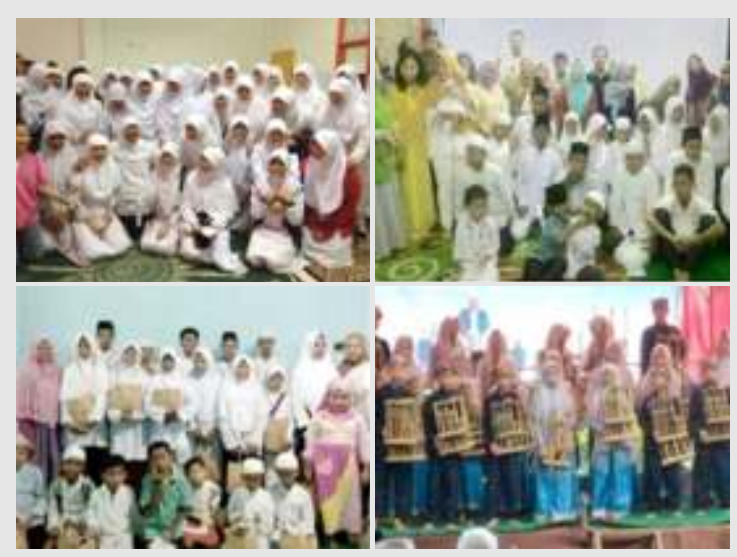

Gambar 1. Kegiatan di Yayasan Baiturrahman

\section{Profil Yayasan Rahmatan Lil Allamin}

Adapun permasalahan yang ditemui di Yayasan Rahmatan Lil Alamin sebagai berikut:

1. Belum tersedianya fasilitas belajar yang memadai.

2. Minimnya motivator atau pengasuh yang memiliki konsentrasi pada pelajaran.

3. Keterbatasan tenaga pengawas belajar.

4. Tempat belajar yang sangat terbatas dibandingkan dengan jumlah siswa-siswi panti.

5. Minimnya tingkat pendidikan pengawas yang tidak memiliki orientasi prestasi.

6. Bertambahnya jumlah penghuni panti membuat kondisi panti tidak layak.

7. Minimnya sarana prasarana yang dimiliki.

Lebih jelasnya berkaitan dengan permasalahan tersebut dapat dilihat pada Gambar 2 dibawah ini:

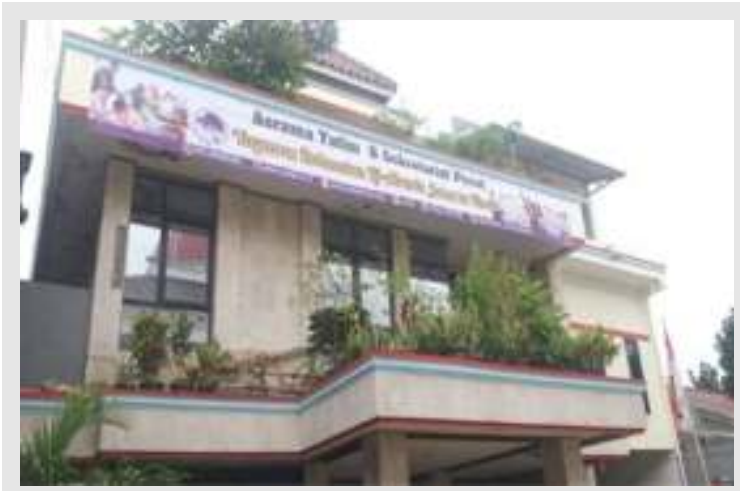

Gambar 2. Asrama Panti Asuhan Yayasan Rahmatan Lil Alamin

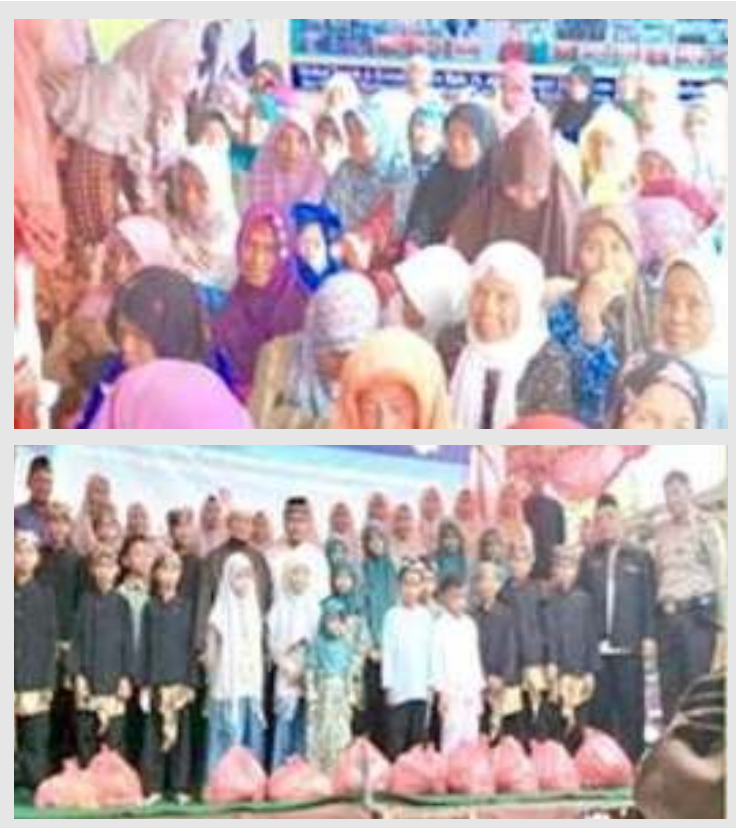

Gambar 3. Kegiatan di Yayasan Rahmatan Lil Alamin

\section{RUMUSAN MASALAH MITRA}

Berdasarkan hasil indentifikasi permasalahan dari 2 (dua) Yayasan Rahmatan Lil Alamin dan Yayasan Baiturrahman dapat dilihat dalam Tabel 1.3 dibawah ini:

Table 2. Data Permasalahan

Yayasan Rahmatan Lil Alamin dan Yayasan Baiturrahman

\begin{tabular}{lll}
\hline No & \multicolumn{2}{c}{ Yayasan } \\
\hline & Rahmatan Lil Alamin & Baiturrahman \\
\hline $\mathbf{1}$ & $\begin{array}{l}\text { Rendahnya rasa } \\
\text { percaya diri }\end{array}$ & $\begin{array}{l}\text { Buruknya kondisi } \\
\text { lingkungan }\end{array}$ \\
\hline
\end{tabular}




\begin{tabular}{cll}
\hline $\mathbf{2}$ & $\begin{array}{l}\text { Rendahnya motivasi } \\
\text { belajar }\end{array}$ & $\begin{array}{l}\text { Merasa minder tidak punya } \\
\text { orang tua }\end{array}$ \\
\hline $\mathbf{3}$ & $\begin{array}{l}\text { Rendahnya daya } \\
\text { konsentrasi }\end{array}$ & $\begin{array}{l}\text { Prestasi sekolah sangat } \\
\text { rendah }\end{array}$ \\
\hline $\mathbf{4}$ & $\begin{array}{l}\text { Kurang minat dalam } \\
\text { berprestasi }\end{array}$ & $\begin{array}{l}\text { Merasa anak miskin dan } \\
\text { berbeda dari yang lain }\end{array}$ \\
\hline
\end{tabular}

Sumber: Hasil survey, Februari 2017

\section{SOLUSI YANG DITAWARKAN}

Berdasarkan hasil kesepakatan dengan Yayasan Rahmatan Lil Alamin dan Yayasan Baiturrahman bersama Tim Pengabdian Masyarakat (Abmas) permasalahan yang akan diselesaikan dalam kegiatan pengabdian masyarakat difokuskan pada 3 (tiga) permasalahan yaitu:

a. Belum adanya pengawasan belajar yang tepat.

b. Belum tersedianya ruang belajar yang memadai.

c. Minimnya kemampuan dan ketrampilan pengajar sebagai pembimbing.

d. Rendahnya motivasi berprestasi.

e. Kurangnya rasa percaya diri.

f. Selanjutnya dapat dilihat pada Tabel 3 sebagai berikut:

Target luaran dalam kegiatan Program Kemitraan Masyarakat (PKM) ini sebagai berikut:

1. Tersusunya pola pikir baru pada siswa-siswa.

2. Tertatanya sistem mentalitas yang baru.

3. Meningkatkan kemampuan dan ketrampilan dengan pelatihan berbasis hypnosis, dalam rangka peningkatan rasa percaya diri.

4. Meningkatkan kemampuan dan ketrampilan dengan pelatihan berbasis hypnosis, dalam rangka peningkatan rasa percaya motivasi belajar.

5. Meningkatkan kemampuan dan ketrampilan dengan pelatihan berbasis hypnosis, dalam rangka peningkatan rasa percaya diri.
6. Meningkatkan kemampuan dan ketrampilan dengan pelatihan berbasis hypnosis, dalam rangka peningkatan daya konsentrasi.

7. Meningkatkan kemampuan dan ketrampilan dengan pelatihan berbasis hypnosis, dalam rangka peningkatan daya saing.

8. NEM siswa-siswi meningkat.

9. Artikel ilmiah dalam jurnal internasional, dipublikasi melalui media online.

\section{METODE PELAKSANAAN}

Kekuatan pikiran mempunyai peranan yang sangat menentukan prestasi siswa-siswi, karena keberhasilan berprestasi sangat tergantung kepada rasa percaya diri. Untuk itu diperlukan penguatan ego strengthening melalui model sugesti hypnosis berdasarkan kriteria kebutuhan kejiwaan para siswa dengan strategi sebagai berikut:

a. Dalam pengelolaan prestasi siswa harus didukung oleh sarana prasarana berbasis pada berbasis hypnosis. Hypnosis menggunakan kekuatan alam bawah sadar sangat efektif membentuk perilaku siswa. Filosofinya adalah membentuk siswa-siswi menggunakan sesedikit mungkin deraan fisik atau jenis hukumann. Manfaatnya adalah meningkatkan produktivitas, prestasi, daya saing dan daya konsentrasi serta mengurangi dampak depresi rasa percaya diri yang tinggi.

b. Ada beberapa manfaat yang ditawarkan oleh penggunaan Model Hypnosis antara lain:

1. Efisien dalam mendidik siswa.

2. Pola belajar lebih baik.

3. Mendukung anak-anak menuju prestasi akademis lebih tinggi.

4. Pola elajar lebih terkendali.

5. Membaiknya rasa percaya diri anak-anak.

Figure 3. Solusi Yang Ditawarkan Dalam Menyelesaikan Permasalahan Mitra

\begin{tabular}{ccll}
\hline No & \multicolumn{1}{c}{ Permasalahan } & \multicolumn{1}{c}{ Solusi } & \multicolumn{1}{c}{ Keterangan } \\
\hline 1 & Kurangnya rasa percaya diri & $\begin{array}{l}\text { Hypnosis dengan sugesti meningkatkan } \\
\text { rasa percaya diri }\end{array}$ & Rasa percaya diri akan meningkat \\
\hline 2 & Motivasi belajar sangat rendah & $\begin{array}{l}\text { Hypnosis dengan sugesti meningkatkan } \\
\text { motivasi belajar }\end{array}$ & Motivasi meningkat \\
\hline 3 & Daya konsentrasi rendah & $\begin{array}{l}\text { Hypnosis dengan sugesti meningkatkan } \\
\text { daya konsentrasi }\end{array}$ & Daya konsentrasi meningkat \\
\hline
\end{tabular}

Sumber: Hasil survei, Oktober 2019 
Tapi pada dasarnya model hypnosis memiliki banyak manfaat selain merubah mindset seseorang secara mudah juga sangat sederhana dalam pengerjaannya, karena bisa dilakukan oleh siapa saja.

Untuk mewujudkan program PKM tersebut, dirumuskan skema kegiatan pada Gambar 4 (empat) sebagai berikut:

\section{PERMASALAHAN}

1. Belum tersedianya fasilitas belajar yang memadai.
2. Minimnya motivator atau pengasuh yang memiliki konsentrasi pada pelanaran.

3. Keterbatasan tenaga pengawas belajar.

4. Tempat belajar yang sangat terbatas dibandingkan dengan jumlah siswa-siswi panti.

5. Minimnya tingkat pendidikan pengawas yang tidak memiliki oriemtasi prestasi.

6. Bertambahnya jumlah penghuni panti membuat kondisi panti tidak layak.

7. Minimnya sarana prasarana yang dimiliki.

\section{Solusi 1}

HypnoEdukasi merupakan teknik model

Table 5. Skema Kegiatan PKM

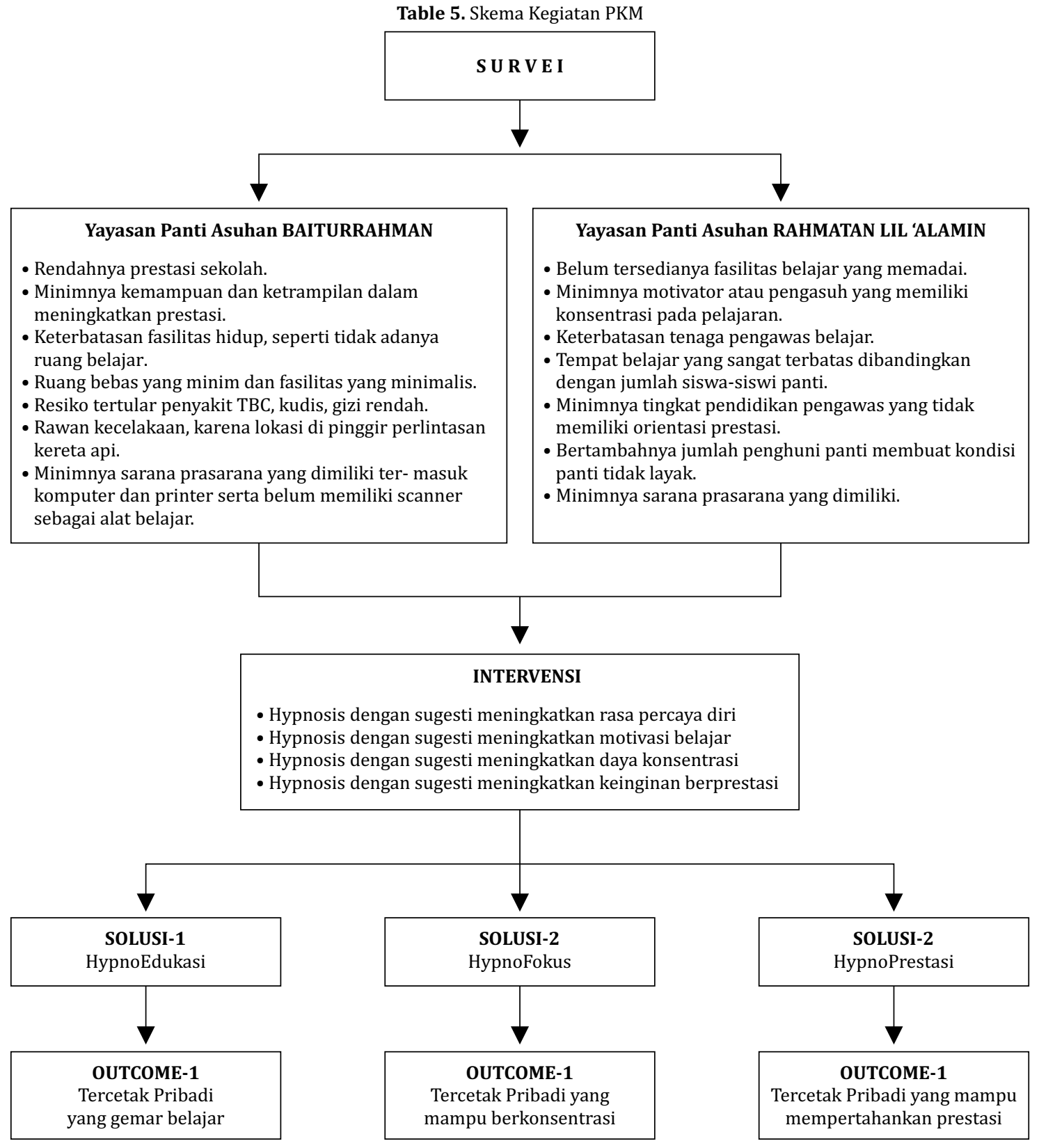


hypnoais diperuntukkan kepada siswa-siswi yang memiliki kesulitan belajar, karena lelah, bosan, kurang ada minat dan kurang memiliki keinginan berprestasi. HypnoEdukasi adalag solusi yang tepat, dengan HypnoEdukasi siswasiswi akan mampu merasa nyaman belajar, timbul motivasi yang menggebu-gebu untuk tergerak untuk belajar dan ingin senantiasa berada di seputar tas dan buku pelajaran.

\section{Solusi 2}

HypnoFokus adalah model hypnosis yang menekankan pada daya konsentarasi belajar, dengan HypnoFokus siswa-siswi akan mampu duduk dan fokus pada apa yang ia kerjakan secara maksimal. Siswa-siswi akan disugesti agar mampu menetapkan dan mendisiplinkan otaknya untuk tetap berhenti fokus pada hal yang disugestikan.

\section{Solusi 3}

HypnoPrestasi adalah model hypnosis bagi mereks yang sudah memiliki prestasi, agar mampu memepertahankan prestasinya untuk mempertahankan staminanya agara bisa menjadi yang terbaik. Sugesti yang dimasukkan ke dalam alam bawah sadar adalah sugesti untuk membarakan semangat menjadi yang terbaik dan menang ataupun memiliki prestasi terbaik di antara para rival atau kompetitor yang lain.

\section{Output}

1. Solusi 1: Tercetak Pribadi yang gemar belajar.

2. Solusi 2: Tercetak Pribadi yang mampu berkonsentrasi.

3. Solusi 3: Tercetak Pribadi yang mampu mempertahankan prestasi.

\section{HASIL DAN PEMBAHASAN}

Kegiatan PKM semester Genap Tahun Ajar 2019/2020 ini dimulai dari bulan Oktober 2019 sampai dengan Februari 2020. Kegiatan dimulai dari pengamatan dan diskusi terkait gambaran mwengenai permasalahan mitra masyarakat mengenai pengelolaan rasa percaya diri.

Kegiatan PKM ini dilaksanakan secara bertahap selama 3 bulan, mulai dari tahap persiapan sehingga pelaporan. Berikut adalah tahapantahapannya: Setelah dilakukan pretest kepada para peserta yaitu siswa dan siswi sekolah menengah tingkat atas di kedua Yayasan tersebut di atas Serang dan Jonggol yaitu dengan uji validitas. Hal ini dilakukan untuk mengetahui pengetahuan dan kesadaran dari siswa dan siswi sekolah perlunya meningkatkan prestasi belajar. Terdapat beberapa teknik atau tahapan dalam menyelesaikan permasalahan melalui program pelatihan:

1. Tahap pertama

Melakukan analisis terhadap program-program yang akan diberikan pada pelatihan. Kami melakukan pematangan konsep pelatihan yang terdir i dari materi, pserta, fasilitator, perijinan dan pembagian tugas.

2. Tahap kedua

Pelaksanaan program pelatihan ini sesuai dengan rentang waktu yang sudah di tentukan sebelumnya, siswa siswi akan diberikan simulasi yang berkaitan dengan materi. Simulasi yang diberikan dapat berupa tip dan cara yang langsung diaplikasikan dan bagaimana yang benar pada kehidupan seharihari. Selain materi yang telah diberikan simulasi juga dapar berupa tips dan gamesgames kecil yang dapat membantu peserta memahami cara mengaplikasikan seetiap materinya.

3. Tahap ketiga

Peserta akan diberikan umpan balik mengenai program pelatihan yang telah dilaksanakan. Hal ini akan menjadi pertimbangan dalam kontinuitas program kegiatan pengabdian kepada masyarakat. Selain itu, akan diberikan juga bentuk apresiasi bagi peserta yang terbaik agar para peserta bersemangat lagi untuk belajar.

4. Evaluasi

Evaluasi akan dilakukan untuk mengetahui sejauh mana pencapaian program kegiatan pengabdian. Evaluasi yang akan dilakukan oleh tim pengabdian setelah pelakasanaan program, sebagai berikut:

a. Evaluasi terhadap materi: materi yang diberikan mudah dimengerti dan dipahami 
peserta, materi yang diberikan sesuai dengan program yang dibuat, matri relevan dengan permasalahan yang dihadapi oleh peserta.

b. Evaluasi terhadap fasilitator: penyampaian yang jelas dan tepat sasaran, kemam- puan dalam memandu kegiatan berjalan sesuai dengan program yang dibuat. c. Evaluasi terhadap pelatihan: kenyamanan tempat pelatihan, kelengkapan peralatan pelatihan.

Dengan adanya hypnoedukasi, maka prestasi siswa-siswi meningkat menjadi sangat motivatif dan memilik gairah belajar dan bersemangat.

\section{DAFTAR PUSTAKA}

De Vos, H.M. \& Louw, D.A.m (2006). The Effect of Hypnotic Training Programs on the Academic Performance of Students, American Journal of Clinical Hypnosis.

Elahi, Z, Boostani, R \& Nasrabadi, Motie (2013). Estimation of Hypnosis Susceptinility Based On Electrencephalogram Signal Features, Scientica Iranica.

Faeni, Dewi., HypnoParenting (2015), Psychoeducation for High Achiever Children, MI- ZAN Publication. Faeni, Dewi, HypnoBeauty (2016), Hypnosis for Women High Achievers, Qanita Publi-cation.

Faeni, Dewi, HypnoAchievement (2014), Hypnosis for Athletes and Education, Qanita Publication.

Krippner, Stanley (2016). The Use of Hypnosis and the Improvement in Academic Acheivement, Reasearch Gate.

Lewin, Kurt, (1996). Human Behavior on Organization, Wiley Publication, Sixteenth Edition.

Maryan, Simon (2011). Academic Performance and Hypnosis, Delhi Psychiatry Journal.

Papadopoulos, Timothy, Pamila, Rauno K., Kirby, John (2014). Cognition, Intelligence, and Achievement: A Tribute to J.P.Das, Indian Journal of Psychology.

Schreiber, Elliott H. (1992). A Study of Hypnosis In Improving Academic Achievement of College Students, Psychologival Reports.

Schreiber, Elliott H. (2016). Use of Group Hypnosis to Improve College Students' Achievement, Sage Journals.

\section{LAMPIRAN 1}

\section{Peta Lokasi Yayasan Baiturrahman dan Yayasan Rahmatan Lil Alamin}
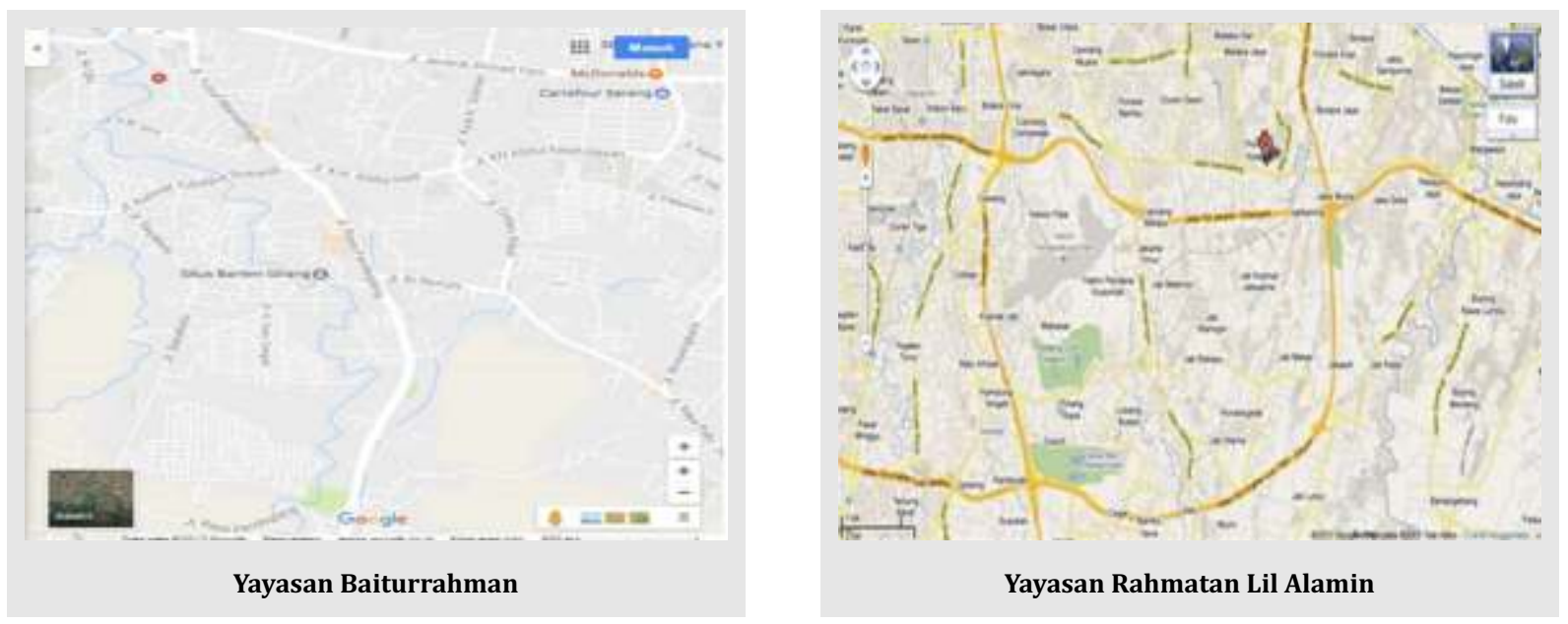